\title{
Troubling "understanding mathematics in-depth": Its role in the identity work of student-teachers in England
}

\author{
Sarmin Hossain • Heather Mendick • Jill Adler
}

Published online: 5 April 2013

(C) The Author(s) 2013. This article is published with open access at Springerlink.com

\begin{abstract}
In this paper, we focus on an initiative in England devised to prepare nonmathematics graduates to train as secondary mathematics teachers through a 6-month Mathematics Enhancement Course (MEC) to boost their subject knowledge. The course documentation focuses on the need to develop "understanding mathematics in-depth" in students in order for them to become successful mathematics teachers. We take a poststructural approach, so we are not interested in asking what such an understanding is, about the value of this approach or about the effectiveness of the MECs in developing this understanding in their participants. Instead we explore what positions this discourse of "understanding mathematics in-depth" makes available to MEC students. We do this by looking in detail at the "identity work" of two students, analysing how they use and are used by this discourse to position themselves as future mathematics teachers. In doing so, we show how even benign-looking social practices such as "understanding mathematics in-depth" are implicated in practices of inclusion and exclusion. We show this through detailed readings of interviews with two participants, one of whom fits with the dominant discourses in the MEC and the other who, despite passing the MEC, experiences tensions between her national identity work and MEC discourses. We argue that it is vital to explore "identity work" within teacher education contexts to ensure that becoming a successful mathematics teacher is equally available to all.
\end{abstract}

Keywords Teacher education · Mathematics Enhancement Course · Understanding · Identity work $\cdot$ Poststructuralism $\cdot$ Colonialism $\cdot$ Equity

\section{Introduction}

There has been much debate within mathematics education research about what mathematics knowledge is needed for teaching. The majority of this has focused on primary and

S. Hossain $(\varangle) \cdot$ H. Mendick

Brunel University, Kingston Lane, Uxbridge Middlesex UB8 3PH, UK

e-mail: sarmin.hossain@brunel.ac.uk

J. Adler

Kings College London, Franklin-Wilkins Building, Waterloo Road, London SE1 9NH, UK 
elementary teachers of mathematics (for example, Ball, Thames \& Phelps, 2008; Hill, Rowan \& Ball, 2005; Ineson, 2011; Ma, 1999; Rowland, Turner, Thwaites \& Huckstep, 2009). However, these debates have also been mobilised in relation to secondary mathematics teachers (e.g. Watson, 2008; Zaskis \& Lekin, 2010) notably, in England, in the context of teacher shortages and the consequent use of "non-specialists" to teach mathematics (Smith, 2004). In this paper, we focus on an initiative in England devised to prepare nonmathematics graduates to train as secondary mathematics teachers through a 6-month Mathematics Enhancement Course (MEC) designed to boost their subject knowledge. The documentation for this course focuses on the need to develop "understanding mathematics in-depth" (UMiD) in students in order for them to become successful mathematics teachers (Adler et al., 2009). It is underpinned by Ma's (1999) influential work on "profound understanding of fundamental mathematics" (PUFM) and its centrality to Mathematics Knowledge for Teaching (MKT). In this paper, we take a poststructural approach, so we are not interested in asking what such an understanding is, about the value of this approach or about the effectiveness of the MECs in developing UMiD in their participants (but see Adler et al., 2009). Instead we explore what positions this UMiD discourse makes available to MEC students. We do this by looking in detail at the "identity work" (Mendick, 2006; Smith, 2012) of two students, analysing how they use and are used by this discourse to position themselves as future mathematics teachers.

In this way, we are responding to an invitation in Nolan's (2011) reflective study exploring why prospective mathematics teachers do not take on inquiry-based approaches in the classroom. Nolan, drawing on concepts from Bourdieu, speculates that teaching for understanding and criticality may have become an orthodoxy within mathematics teacher education, and ends by suggesting: "Perhaps a critical next step in a reflective study of this nature would be to ask the question of how my practice as a teacher educator and faculty advisor must be (cross)examined as its own site of (re)production" (p. 214). We would contend that the value of UMiD has become part of this commonsense orthodoxy in mathematics education. Adler et al. (2009) suggest as much, basing this claim on their analysis of the talk of MEC students. All social practices are implicated in processes of inclusion and exclusion, so when these practices take on the status of commonsense, and even are presented as emancipatory, it is important to interrupt them. Postststructural theory offers a way to do this. For, "the value of theory lies in its power to get in the way: to offend and interrupt. We need theory to block the reproduction of the bleeding obvious, and thereby, hopefully, open new possibilities for thinking and doing" (MacLure, 2010, p. 277). Thus we begin by elaborating what taking a poststructural approach entails.

\subsection{Taking a poststructural approach to "understanding mathematics in-depth"}

As stated above, in distinction from most research on MKT, in this paper we are not interested in exploring what this is but what it does. So we do not want to develop frameworks for teacher knowledge, as Ball (for example, Ball \& Bass, 2000) does, or to discover the "best" forms of mathematical understanding for supporting pedagogy, as $\mathrm{Ma}$ (1999) does. Instead in taking a poststructural approach, we see all research as not describing a prior reality but as constructing "reality" (Foucault, 1972; Walkerdine, 1997; Walshaw, 2001).

Discourses are at the centre of a poststructural approach. MacLure, attempting "to define a discourse-based approach to educational research", suggests that "one of the more general things I might say is that you have to suspend your belief in the innocence of words and the transparency of language as a window on an objectively graspable reality" (MacLure, 2003, 
p. 12, original emphasis). Discourses are knowledges about the world enacted within language, in its broadest sense (written, verbal, visual, sonic, bodily etc.), through which objects, such as the "good mathematics teacher" and "in-depth understanding" come into being. They are powerful stories which set limits on our possibilities for thinking, saying and acting, and so for being. Walkerdine (1997), following Foucault (1980, p. 193), calls them: "fictions functioning in truth". We are interested in what the UMiD discourse fictions into truth for MEC students. What does it make possible for them to be and what does it render impossible? And, how does this relate to other aspects of their identity work? Poststructuralsim works against the humanist, enlightenment idea that there is an essential inner self. Thus:

The human being ... is understood as a text, as a composition, as a bricollage, or as a performance without an essential core. The self becomes 'subjectivity,' which is the effect of material practices, of discourses, rather than a prior unity. Subjectivity is theorized as being constructed along with objective knowledges. Subjectivity assumes that systems of reasoning do not just produce object knowledges, but they also affect how young people or teachers experience and understand themselves. (Lesko, 2001, p. 14)

As Lesko describes here, poststructuralism offers a particular way of understanding the relationship between structure and agency. Selves are both subjected by and subject of discourses. The poststructural subject is both constrained, being always within discourse, and agentic, active in negotiating its own discursive positioning. The power of discourse is both oppressive, in setting limits on what we can be, and productive, in offering us possibilities for being at all (Foucault, 1980). Thus, our positioning, including that of MEC students, is both the effect of prior power as well as the condition of possibility for a re-imagined form of agency. As Butler (1999, p. 189) writes: "to enter into the repetitive practices of this terrain of signification is not a choice, for the ' $\mathrm{I}$ ' that might enter is always already inside: there is no possibility of agency or reality outside of the discursive practices that give those terms the intelligibility that they have." Using this approach, we analyse how MEC students work and are worked by the UMiD discourse. That is, how the discourse becomes part of their ongoing identity work. The phrase identity work, like the term subjectivity, emphasises that identity is not essence but active accomplishment, neither fixed nor singular but multiple and fractured. However, despite this multiplicity, not all positions are equally available to all and certain labels, emotions and stories get stuck to particular bodies (Ahmed, 2004). Indeed, as Skeggs (2004) argues, some bodies are able to position themselves as mobile, enterprising selves while others become fixed in place.

In doing this, our aim is to trouble UMiD, something that, as mentioned above, has acquired the status of a taken-for-granted good within mathematics education. Indeed, as Schoenfield observed, Ma's work is "the only manuscript I know that has the attention and favor of both sides of the "math wars"' (quoted in Shulman, 1999, p. xii). However, instead of reading this as a point in its favour, we would argue this is a compelling reason to question it. We follow Hardy (2009) who has illustrated how, in a "faintly noticed essentialising shift", 'the question 'What's the problem with primary students' mathematics teaching?' can become 'What's the problem with primary students' mathematics?'” (p. 387). She notes, not simply how such teachers are constructed as lacking knowledge of mathematics but as lacking the right sort of knowledge. For example she quotes from "the introduction to a recent pre-service course textbook, Mathematical Knowledge for Primary Teachers ... : 'One of the problems to be overcome by many seeking to teach mathematics to young children is that they have the wrong kind of understanding of their subject.' (Suggate, 
Davies, \& Goulding, 2006, p. preface)" (Hardy, 2009, p. 387). We can see similar judgements and distinctions operating throughout the research tradition that led to Ma's work on PUFM. This reproduces a distinction from Skemp's (1976) influential early work between relational and instrumental understanding (paralleled in conceptual and procedural understanding, Hiebert and Lefevre, 1986) with the former oriented towards connections and relations between mathematical concepts and the latter towards mathematical performance and procedures. Skemp's and Ma's work carries strong judgements about which forms of understanding are most valued: the terms deep and profound operate in implicit opposition to surface, shallow, superficial. One form of understanding is "right", authentic and "real"; the other is "wrong", inauthentic, "fake".

Our work is not intended as an argument against the works of Ma, Skemp, Ball et al. in the conventional sense. But we do want to join with other poststructural work in mathematics education (e.g. Hardy, 2009; Llewellyn, 2012; Mendick, 2006; Smith, 2012; Walkerdine, $1988,1998)$ in calling attention to what constructing mathematics subject knowledge in this way does. While it is important to give people access to the high status knowledge that is mathematics, we would insist on the need for vigilance of how practices of mathematics education are implicated in processes of social inclusion and exclusion. A focus on subject knowledge for teaching, and on understanding within this, is much more common in mathematics and science than in other subjects (Ball et al., 2008). It is thus part of the constellation of power/knowledge (Foucault, 1980) through which mathematics distinguishes itself as a subject. Smith (2010) shows that oppositions between breadth and depth are central to the representation of mathematics, its power in the curriculum and practices of exclusion. She does this by analysing how highly-valued depth is associated with elite mathematics and devalued breadth with mathematics for the masses. Thus, we are also interested in how discourses of understanding articulate with widespread patterns of inclusion and exclusion from mathematics that have been shown to operate, for example, by class, gender and race (e.g. Gates, 2001; Martin, 2010; Mendick, 2008; Solomon, 2008). Work by Davis and Martin (2008), Llewellyn (2012), Mendick (2006) and Walkerdine $(1988,1998)$ shows how some white middle-class males are more likely to be positioned as and to position themselves as having "real understanding" of mathematics; whereas girls and women and those from minority ethnic and/or working-class backgrounds may have their achievements undermined by these being positioned as the result of the wrong kind of understanding. Our task here is to begin the project of looking at who is included and excluded and how within the emergent discourses of the MEC. Before exploring how this played out within our data we describe our methodology.

\subsection{Collecting and analysing data on "understanding mathematics in-depth"}

This paper draws on empirical data from the QUANTUM-UK study. The study, funded by King's College London, is exploring how Mathematics Knowledge for Teaching (MKT) and, specifically, UMiD is being constituted within the MEC (Adler et al., 2009). The study extends the ongoing research and development project QUANTUM in South Africa. The South African project has been instrumental in setting up programmes for mathematics teachers who are "under qualified" in mathematics. Since 2003, QUANTUM has been research focused, investigating the kind of mathematics courses on offer across institutions with particular focus on how mathematics comes to be constituted in and across courses that have both mathematical and pedagogical intentions.

As stated earlier, the rationale for the MEC in England is to encourage and attract nonmathematics graduates into retraining as secondary mathematics teachers. To qualify for the 
MEC, graduates are required to have some experience of post-secondary mathematics. After completion of the course, successful students proceed to a PGCE, a one year postgraduate course of teacher training. MEC programmes are thus focused on both deepening and extending mathematical knowledge in ways seen as appropriate to the profession of teaching. The significance of the MEC as an empirical site is thus not only that it provides an alternate route into teaching, but also that it offers an example where the specificity of MKT is expressed through an explicit commitment in course materials to a "profound understanding of fundamental mathematics, emphasising deep and broad understanding of concepts, as against surface procedural knowledge" (Teacher Training Agency [TTA], 2003, Specification for Mathematics Enhancement Course, unpublished, p. 3).

The empirical work for the QUANTUM-UK study commenced in 2009 and consisted of two phases. In phase one, four MEC tutors and eighteen students across three institutions were interviewed. Phase two involved re-interviewing these students during their PGCE year and a survey of these and other MEC qualified teachers who are in the profession. In this paper, we draw on the student interview data from phase one. The selection of students for these interviews was purposive, guided by a set of criteria so that participants included those with: mathematical and non-mathematical backgrounds; different cultural and educational backgrounds; and varied levels of participation and performance in the course. Of the 18 participants, 14 were educated in the UK, two in Nigeria, one in Cyprus and one in Pakistan. Three joined the MEC immediately after finishing their undergraduate degrees, while four had had a short career and eleven a long career before entering the programme. Only five had any form of teaching experience. They also started with varied mathematical backgrounds and qualifications. While most (14) had either an A-level in mathematics (a university entry qualification taken at $18+$ ) or equivalent, four students had only the equivalent of a pass in GCSE (the compulsory school leaving examination in mathematics taken at $16+$ ) with some mathematicsrelated study or experience in their education and work histories.

The in-depth semi-structured interviews were used to probe students about: their motivations for joining the MEC, their experience of the course, how and in what ways their learning of mathematics in the MEC had been different to their learning of mathematics at school and/or at university and how they interpreted UMiD. As part of this they were asked to order five different statements related to UMiD elicited from earlier interviews with MEC tutors. The statements were: "Understanding mathematics in-depth means being able to:

- Justify your mathematical thinking.

- Explain and/or communicate mathematical ideas and thinking to others.

- Understand why and how these procedures work.

- Make the connections between concepts and between procedures.

- Identify structure and generality.

The interviews lasted between 32 and $68 \mathrm{~min}$, were audio-recorded and transcribed. The research adopted a collaborative approach. As part of this, each interview was conducted by a researcher from King's College London (either Sarmin or Jill) and one of the MEC tutors from a different institution. While the interviews were not directed towards subjectivities, they were designed to allow interviewees to talk about the MEC and their understandings of it as a mathematics course and/or a teaching course, thus opening spaces for them to position themselves.

Initially the data were analysed thematically focusing on: the students' backgrounds, concerns and motivations for pursuing the MEC; their preferences within MEC activities; their orientations to mathematics; and their learning and interpretation of UMiD. However, as Sarmin and Jill interacted with the data, other interesting themes started to emerge for 
them related to the identities of the students and the coding was extended to address these. They found that students talked about mathematics and teaching elements when making reference to themselves. For example, "I am more mathsy now" and "I am more confident to teach". In these instances the text was coded as "Self and mathematics" and "Self and teaching" respectively. Such statements occurred frequently in the data as did distancing statements about "others", indicating how the students were positioning themselves in mathematics, in teaching or in both mathematics and teaching as they journeyed through the MEC programme.

Sarmin and Heather began discussing this "emergence" of the students' selves. Our interest in the relationship between mathematics and identity work led us to collaborate in exploring how participants positioned themselves and are positioned as mathematicians, teachers and/or mathematics teachers. Our focus on the workings of UMiD within this came from its centrality to the data. However, our focus was supported by our reading of the mathematics education literature and our sense that we could use these data to disrupt the dominant discourse (or orthodoxy).

For the purpose of this paper, we reviewed the 18 student interviews and explored the identity work happening within each interview. We see interviews as spaces in which such identity work takes place: "the processes of interviewing and of being interviewed are not simply about the giving and receiving of information but at least as much about speaking identities into being, solidifying them and constantly reconstituting them through the stories we tell ourselves and each other" (Epstein \& Johnson, 1998, p. 105).

We then selected two students who demonstrate two contrasting positions in negotiating the dominant UMiD discourse to construct themselves as be(com)ing mathematicians, teachers and/or mathematics teachers. We re-analysed these two interviews poststructurally using an approach from Davies and Harré (1990). Following Foucault, they define discourse as "a multi-faceted public process through which meanings are progressively and dynamically achieved" and argue that "the constitutive force of each discursive practice lies in its provision of subject positions" (p. 47). The work of the analyst then becomes identifying the ways in which speakers position themselves and are positioned within discursive encounters and the emotional commitments these entail (Ahmed, 2004).

As a result of this analysis we noted that some participants found it easier to take-up the dominant discourse promoted within the MEC (and the interview): that UMiD is a necessary foundation for teaching the subject. From the literature discussed in the last section, we might expect this discourse to be a better fit with the identity work of the white male middle-class participants - also echoing Walkerdine's (1984) analysis of the discourse of the active child within child-centred education. However, although among our participants, white middle-class men were more likely to use this discourse to support their constructions as teachers and mathematicians, this was not exclusively so. Two of those who did so were white men (out of five interviewed), one a white woman and one a British Pakistani woman. It is with one such participant, whom we have called Gary, with whom we start. By focusing on Gary, we want to make the familiar strange. We then move on to look at Lola who, while successful in that she passes the MEC programme, resists the dominant discourse. The contrast between Gary and Lola shows how some students fit better than others; some students' ways of being a teacher and being mathematical are legitimate within the MEC and others are not.

1.3 Gary's story: "understanding mathematics in-depth" and white middle-class masculinity

While all but 2 of the 18 students took up UMiD in order to support their identity work as a teacher, Gary is one of only four who took it up positively to support both their mathematics 
and teaching identity work. Thus, we have chosen Gary because he is able to take on the dominant UMiD discourse to construct himself as both a mathematician and a future teacher. Within the MEC, Gary is "normal" and hence relatively invisible. It is important to draw attention to such privileged positions.

For Gary becoming a mathematics teacher represents an important shift. Within the interview he articulates this by constructing a progressive narrative of movement: from youth to maturity and from his previous self-oriented career in retail management to one in "teaching [which] is completely different: you get some benefit yourself, and obviously you're benefiting the kids". He uses the UMiD discourse within these shifts, for example, "I was very young then [at school] and just didn't get it as such ... because I'm older, em, I understand, I can understand the sort of real life concepts now". As we will show, the discourse of in-depth understanding allows him to position himself as a better (potential) mathematics teacher than those entering the profession via the PGCE alone and a better mathematician than those who have pursued an undergraduate mathematics degree.

As mentioned, Gary writes himself as changed and changing within multiple discourses. In particular he constructs himself as changing in relation to his views on the MEC's practices (for example, not being given the answers initially "got on my nerves" but "I know why now, after six months that they did it that way") and the MEC's value for him.

When I was told I couldn't go on the PGCE and had to go on the MEC, it was quite disheartening, thinking: 'Well, okay, I'm not good enough,' but ... they're trying to get the people on to PGCE that are going to stick it, em, and have got the maths knowledge which you need on the PGCE, because it is obviously quite intense, em. I would say it gives you a very wide range and an in-depth knowledge of maths. Coming from the background [I] did, there was a lot of rote learning, 'This is the information you need to learn, learn it'. ... This course, it gives you a lot of background in terms of history and culture, as well as proofs.

Here we see the dominant positioning of "in-depth knowledge" as opposed to rote learning as a better foundation for teaching, so that an initially "disheartening" decision which he took to mean "I'm not good enough" can be re-inscribed as part of becoming a better teacher. As he says later: "I think we're going to be more prepared than the PGCE students next year that start who are coming straight from university or have just got a straight maths degree because we've got the more indepth knowledge". He repeats this opposition and his changed position in relation to it often within the interview. For example: "I was able to do maths, I was good at maths, but I didn't have the understanding and that's what this course I think fundamentally does". So Gary takes on the importance of UMiD. Next we show that this is central to the identity work he does to position himself as a future mathematics teacher.

Gary repeatedly describes how the various aspects of in-depth understanding are vital to teaching: "I think that's half the battle with kids, that you need to show them where it comes from rather than just a case of, "Well, here it is"'. In relation to Pythagoras, he recalls thinking "'Right, I'm going to use that in the classroom", and in relation to knowing the history of maths and proofs, he says: "Having that understanding behind you to go on the classroom is, could be very powerful, em, and getting that across in all different topic areas as well, I think that's the, for me that's what a depth of understanding means". His strong orientation towards teaching 
is clear in his choice of the school intervention as the element of the MEC that has most significantly impacted on his learning:

I think that's been the most powerful, (1) in showing us that we're in the right place, em, and (2) in that seeing how kids learn and what we've got to do between now and starting teaching, to be able to get the information or knowledge we've got and pass it on to them. ... I've got to be $100 \%$ with the material to start with and then I need to know how to get that across and that intervention did, for me, it brought to the front of what I need to learn.

For Gary, being in school "seeing how kids learn" is what matters and orients "what I need to learn". This requires a shift to be(com)ing a mathematician since: "I want to be the best person I can in the classroom in front of them, and also they need to respect me that I know as much as I can". When asked directly "Do you consider yourself a mathematician?", Gary replies, "I do now. ... I didn't before I started the course but I do now". He explains this change in terms of "the interest in maths now, I've had a lot of time out", drawing again on the discourse of his developing maturity. "In-depth understanding" is also central to his positioning himself as a mathematician:

It's having a deeper understanding of maths, I think, that makes you a mathematician ... rather than the amount, so I'd still say I'm a mathematician even though I haven't got a clue about most of the stuff I've done at university level ... but that will come over time, because it's having an interest in maths now that I will spend my spare time [laughter] reading about maths.

Here the discourse of depth allows him to write himself as (potentially) a better mathematician than he would have been had he taken mathematics at university when he was younger, something: "in hindsight" he "thought maybe I should have done". At school he "was pushed ... to do chemistry", now he is taking on his educational choices as his own as he must to produce himself as a mature, autonomous individual (Rose, 1999). He is able to draw on geek discourses which position being a mathematician as, "sad" and in the following extract as "scary" and "silly" : "in every situation there's always, you think, 'Well, this is the maths of it,' it's scary the things that come about, and to the point where my wife's going, 'Shut up, you're being silly now.' [Laughter] And I've only been doing it for six months". Research shows that this is a position much more easily occupied by those who are white, male and middle-class (Mendick \& Francis, 2012; Moreau, Mendick \& Epstein, 2010).

In summary, Gary was one of a majority of participants who took up UMiD to position himself as a becoming mathematics teacher. He followed the dominant discourse that constructed UMiD as vital to teaching, and thus key to his goal of becoming the "best person" in the classroom. He did not consider himself a mathematician before the course. However, the MEC discourse of UMiD had enabled him to position himself as (potentially) a better mathematician than he would have been if he had studied for a mathematics degree. Through Gary's story we can see how the dominant MEC discourse of UMiD supports stories of progress and becoming for some MEC students. However, even for Gary there are some tensions. Notably, claiming a position of mathematician, within the dominant discourse requires independence from the teacher (Mendick, 2005): “Obviously we've only had a short time to do the section, but I think I will go away and do some more research on it, em, whether that will come into my teaching". Yet Gary wants to be a teacher, and so inscribes this role as vital. Perhaps his shift from youth to maturity is so central to his identity work within the interview because this enables him to resolve this tension by constructing young 
people as dependent, and so in need of teachers, but older people, like himself, as independent. We can also begin to see, in Gary's story, how the opposition between breadth and depth draws on traditional exclusionary discourses of mathematics. For depth is associated with the elite position of the mathematically able as opposed to breadth which is associated with increased access to but decreased quality within mathematics education (Smith, 2010). Through Lola's story which we look at next we explore how particular discourses around culture operate to make it much more difficult for some students to take-up the MEC orthodoxy than it is for Gary.

\subsection{Lola’s story: "understanding mathematics in-depth" and racialised othering}

Lola was brought up and educated in Nigeria. We have selected her because she was one of only two MEC students (the other of whom dropped out) to distance herself from the idea that UMiD is necessary for "good" mathematics teaching. We will argue that this is because she reads the opposition between surface and in-depth understanding culturally, locating the former within her Nigerian school mathematics education and the latter within her English MEC mathematics education. This means that aligning herself with UMiD entails her seeing her Nigerian education, and perhaps by implication her culture, as inferior to English education and culture. However, this creates a tension with her desire to become a good mathematics teacher in England which, within the MEC, requires in-depth understanding. We will suggest that she partially resolves this tension by taking up the UMiD discourse in a limited way in relation to her own mathematics learning, using it to position herself as a becoming mathematician.

When asked for her feelings about the MEC, Lola's are muted in comparison to other participants' enthusiasm: "it's been ok really". She is even critical of how the MEC puts into practice its pedagogic rationale of developing in-depth understanding: "The whole idea is for us to get a deeper understanding and sometimes we are rushed, so it's not very efficient." Thus central to distancing herself from the MEC is her specific distancing from the idea that becoming a mathematics teacher requires UMiD and that being a good mathematics teacher requires cultivating such understanding in others.

While all but two MEC participants relate UMiD to teaching, Lola does this only at one remove through telling us what her lecturers have said. For example, she says, "it was quite a challenge when ... a lecturer come in and he said, 'You cannot tell a student if you multiply by ten, you just add zero'. And I was like, 'Oh my goodness. That's what we always, we have always said that". Here, Lola positions the UMiD discourse as "a challenge" to her. Not only does she locate it in another person, a lecturer, but her construction of a "we" outside of this positions her with/in a Nigerian collective who does mathematics differently. Multiplying by 10 was clearly a resonant example for Lola as she returns to it later in the interview.

I was a bit resistant ... We've lived with this. We still do well. ... But, at the end of the day, you have, you have to look at the other side as well, but people find it difficult, because our lecturer said, 'If someone coming from the primary school has already known that ... multiply by 10 , you just add zero. ...' but where I'm coming from, I don't feel like that that person is dumb.

This extract repeats Lola's locating of the dominant UMiD discourse with her lecturer and of herself with/in a "resistant" "we". We can also see how Lola, wanting to be a successful mathematics teacher in England while also valuing her Nigerian mathematics education, is negotiating conflicting discourses. Thus she offers "you have to look at the other side as 
well" while also defending the "we" who "lived with this" and "still do well", against the risk of their being called "dumb".

Following Hall (1992), we can read Lola's positioning as producing a diasporic "cultural identity" which:

...belongs to the future as much as to the past. ... Cultural identities come from somewhere, have histories. But, like everything which is historical, they undergo constant transformation. Far from being eternally fixed in some essentialised past, they are subject to the continuous 'play' of history, culture and power. Far from being grounded in a mere 'recovery' of the past, which is waiting to be found, and which, when found, will secure our sense of ourselves into eternity, identities are the names we give to the different ways we are positioned by, and position ourselves within, the narratives of the past. (p. 225)

Further, we can understand her resistance to UMiD as a resistance to the (post) colonial gaze that disfigures and destroys the "pasts" of oppressed peoples: "The ways in which black people, black experiences, were positioned and subjected in the dominant regimes of representation were the effects of a critical exercise of cultural power and normalisation" (p. 225). This is part of a process of Othering in which identity is constructed via "establishing opposites and 'others' whose actuality is always subject to the continuous interpretation and re-interpretation of their differences from 'us', and where this designation of others re/produces hierarchical power relations" (Said, 1995, p. 332). As Hall argues, not only is Othering external to the self but "They ha[ve] the power to make us see and experience ourselves as 'Other'” (p. 225, original emphasis).

Unsurprisingly, given this reading, this resistance recurs in her interview:

I learned outside this country, the way of teaching is totally different ... the concept that we knew and just applied, coming here, you need to understand why the concepts came about, how they came about, and you get a deeper understanding. Whereas the kind of knowledge and teaching I've been accustomed to is you get a formula, you understand, you just know the formula, you apply the formula, and get results. But here you need to understand why the formula works.

In using "just" twice to describe what is expected in Nigerian mathematics classrooms Lola may be accepting the MEC positioning of "rote learning" as lesser implicit within the surface/depth opposition (Smith, 2010; Walkerdine, 1998). However, she may also be constructing her Nigerian learning as better because it is more straightforward, rather than making the unnecessary requirement that learners "get a deeper understanding". Similarly she explains:

I think the culture plays a lot of role in the way people are taught there, because in Nigeria, for instance, it's rude to ask an elder, 'Why?' And here, for the ... lecturer to say 'why is the most important letter in the alphabet'. ... You don't ask any questions because you are scared that, er, you, you insult the teacher by asking him or her 'why?' ... and what I understand here is that, as a teacher, you need to know all the ways because the, the student might understand one way better. Whereas where I'm coming from, the teacher teaches whichever one he's [sic] comfortable with, and that's it. ...

But it's so much better if you know all the ways and then whichever one the child is comfortable with, the child will be able to pick it up.

Again Lola initially ascribes the MEC view to her lecturer and relates surface/depth to cultural differences. Interestingly, she ends by saying the MEC position is better, the one 
time in the interview that she clearly affirms the value of UMiD for teaching. However, this comes after a discussion in which depth pedagogies are positioned as part of a pattern of disrespect for elders, in which questioning teachers can only be seen as rudeness and insulting. She could also be giving the interviewers what (she thinks) they want to hear. For this answer receives positive feedback "excellent, excellent" from the MEC tutor interviewer while her previous comments have elicited only more equivocal responses such as "yeah".

The topics Lola uses to illustrate in-depth understanding show the tensions in her position. They are things she already knows from Nigeria: algebra and calculus. About algebra she says: "I've always loved algebra. I've always seen algebra as a very easy to understand subject ... Like also things we were taught now, I have known them before." In this account, there seems to be little that depth added to Lola's knowledge of algebra. She is more positive about depth having given her a "different understanding" of calculus: "I thought, 'How much calculus is there in order to be a module on its own?' because I've done calculus before ... But when we started the course, I went through the history and ... how the calculus came about. It was so much [more] interesting because it was like I'd not done it before, but I had done it before." In addition to history, she identifies connection and application as key elements of UMiD and offers: "if you have a deeper understanding of it, you're not going to be scared of anything because you know there is a solution, or you can attain to solution." However, what is relevant for our purposes here is that Lola positions indepth understanding positively. To end, we explore how she holds this together with her disidentification from it as a basis for teaching.

From the start of the interview, Lola, identifies her choice of teaching as pragmatic ("I thought that the best thing to do is to work around my children and teaching was the best option") and her choice of mathematics as about love ("after all the subjects I looked at, I thought that I loved maths the best"). Her desire to teach is inseparable from her desire to teach mathematics: "that is one of the reasons why I would like to teach maths, because I love maths and the reason why I like maths is because I had a very good maths teacher in my secondary school." It is through her relationship with mathematics that she is able to write herself positively into UMiD. From the proffered definitions, Lola chooses: "Understanding mathematics in-depth means being able to understand why and how these procedures work." Her reason is "because, as a good mathematician, you should be able to understand how a procedure came about, why it works, how it works, and basically, everything about it." "Tell[ing] somebody about it", as a teacher, takes second place to "understand[ing] it yourself", as a mathematician. Similarly when Lola talks in detail about seeing mathematics in "our everyday life" she mentions the pedagogic practice of telling others only when the interviewer asks about this:

It could just be a book sliding from the table, and you think of what was involved. It's just like we're talking of the mechanics, the forces involved, and then it's just so interesting. ... So I think, em, understanding maths is more or less day-to-day living. ... [Do you talk about it more? Have your family and friends noticed?] Oh, yes, they have noticed. ... Now it's like, 'Oh my God, mathematician!' I say, 'No, not yet. I'm still getting there'.

Lola has an ambiguous relationship with being a mathematician. While she denies it here and elsewhere, she claims a position as a "pure mathematician" early in the interview, in distinguishing herself "I love pure mathematics much more than applied mathematics". Overall we would suggest she positions herself as becoming a mathematician. It is this relationship with mathematics that allows her to align with UMiD within the MEC without 
taking on the construction of her Nigerian mathematics education as Other to the dominant Western orientation to teaching for understanding. In summary Lola was one of just two participants who distanced themselves from the dominant MEC discourse of UMiD as a foundation for teaching maths. In her story we can see how depth can work against difference.

\section{Conclusion}

In this paper, we have focused on how two students adopt, rework and/or resist the dominant MEC discourse of UMiD. Of course this forms only one story of the MEC. Other papers will focus on how students have successfully moved into teaching from the MEC and how the MEC inducts them into the UMiD discourse, as indeed this paper shows, and how it supports them in developing an identity in relation to mathematics and teaching. The MEC is a social practice that comes out of mathematics teacher education practice and research which has flourished recently (Adler, Ball, Krainer, Lin \& Novotna, 2005). Now that this field is established we can take a step back. This has been our task in this paper showing how even benign-looking social practices such as UMiD are implicated in processes of inclusion and exclusion.

In summary, our two cases show that: Gary's identity work, despite some tensions, is supported by the dominant UMiD discourse in progressing and (be)coming a mathematician and teacher. This is even to the extent that this discourse allows him to consider that he is a better mathematician than he would have been if he had studied mathematics at degree level and a better teacher than he would have been coming through the conventional route. Lola, on the other hand, although successful in that she passes the MEC, does not fit in the way that Gary does. Her commitment to her Nigerian cultural background leads her to resist the dominant discourse and find a different way of being/becoming a mathematics teacher. However, this is a way that is less legitimate and less legible within the MEC than Gary's.

Although Gary and Lola line up with gender and race in particular ways which fit with patterns in the wider research literature (e.g. Davis and Martin, 2008; Gates, 2001; Llewellyn, 2012; Martin, 2010; Mendick, 2006, 2008; Solomon, 2008; Walkerdine, 1988, 1998), these were not deterministic. For example, Farzana is a student educated in Pakistan and she shares with Lola a similar cultural background, early mathematics education and close relationships with her school teachers. However, she does not position herself against the dominant discourse in the way Lola does. Instead she manages this by distinguishing between the purposes of her Pakistani mathematics education and her MEC mathematics education, seeing the former as directed towards passing examinations and the latter as directed towards becoming a mathematics teacher. However, even in this case the identity work demanded of her is different than for Gary, in that she still has tensions to deal with because she is mediating between two mathematics education contexts and her different investments in them.

We end by pointing out two implications of this paper. First, we need to recognise that the MEC programme is opening up mathematics in general, and mathematics teaching in particular, to a greater diversity of people - with a range of qualifications and cultural backgrounds. This creates a need to consider the various identities that people come in with and how this shapes what is possible for them in the MEC. We also have to ask what our role is as mathematics educators in intervening into and supporting this process. Second, this paper shows that we need more work that does not assume "understanding mathematics indepth" is an unproblematic good and that pays attention to student-teachers' identity work during their courses and when they enter schools. 
Acknowledgments We would like to acknowledge that this paper draws on data from the QUANTUM UK project funded and led by King's College London and which has involved a team of researchers affiliated with Liverpool Hope University (Mary Stevenson, Barry Grantham), University of East London (John Clarke) and Manchester University (Rosa Archer). We are, of course, very grateful to the students who participated in this study. This paper benefited immensely from feedback from Sarmin and Heather's colleagues in the Pedagogy and Professional Practice Research Group at Brunel University and from two anonymous reviewers. Heather would also like to thank Anna Llewellyn for conversations which fed into this paper.

Open Access This article is distributed under the terms of the Creative Commons Attribution License which permits any use, distribution, and reproduction in any medium, provided the original author(s) and the source are credited.

\section{References}

Adler, J., Ball, D., Krainer, K., Lin, F. L., \& Novotna, J. (2005). Reflections on an emerging field: Researching mathematics teacher education. Educational Studies in Mathematics, 60(3), 359-381.

Adler, J., Hossain, S., Clarke, J., Stevenson, M., Grantham, B., \& Archer, R. (2009). Interpretations of, and orientations to, 'understanding mathematics in depth': Students in MEC programmes across institutions. Informal Proceedings of the British Society for Research into Learning Mathematics, 29(3), 1-6.

Ahmed, S. (2004). The cultural politics of emotion. Edinburgh: Edinburgh University Press.

Ball, D. L., \& Bass, H. (2000). Interweaving content and pedagogy in teaching and learning to teach: Knowing and using mathematics. In J. Boaler (Ed.), Multiple perspectives on mathematics teaching and learning. Westport: Ablex Publishing.

Ball, D. L., Thames, M. H., \& Phelps, G. (2008). Content knowledge for teaching: What makes it special? Journal of Teacher Education, 59(5), 389-407.

Butler, J. (1999). Gender trouble: Feminism and the subversion of identity. London: Routledge.

Davies, B., \& Harré, R. (1990). Positioning: The discursive production of selves. Journal for the Theory of Social Behaviour, 20(1), 43-63.

Davis, J., \& Martin, D. (2008). Racism, assessment, and instructional practices: Implications for mathematics teachers of African American students. Journal of Urban Mathematics Education, 1(1), 10-34.

Epstein, D., \& Johnson, R. (1998). Schooling sexualities. Buckingham: Open University Press.

Foucault, M. (1972). The archaeology of knowledge. London: Routledge.

Foucault, M. (1980). In C. Gordon (Ed.), Power/knowledge: Selected interviews and other writing by Michel Foucault. Harlow: Prentice Hall.

Gates, P. (2001). What is an/at issue in mathematics education? In P. Gates (Ed.), Issues in mathematics teaching. London: RoutledgeFalmer.

Hall, S. (1992). New ethnicities. In J. Donald \& A. Rattansi (Eds.), 'Race', culture and difference. London: Sage.

Hardy, T. (2009). What does a discourse oriented examination have to offer teacher development? The problem with primary mathematics teachers. In L. Black, H. Mendick, \& Y. Solomon (Eds.), Mathematical relationships in education: Identities and participation. New York: Routledge.

Hiebert, J., \& Lefevre, P. (1986). Conceptual and procedural knowledge in mathematics: An introductory analysis. In J. Hiebert (Ed.), Conceptual and procedural knowledge: The case of mathematics. Hillsdale, NJ: Lawrence Erlbaum Associates.

Hill, H. C., Rowan, B., \& Ball, D. L. (2005). Effects of teachers' mathematical knowledge for teaching on student achievement. American Educational Research Journal, 42, 371-406.

Ineson, G. (2011). Joining the dots and seeing the whole picture - Initial teacher education for mental mathematics. Unpublished EdD thesis. Uxbridge, Brunel University

Lesko, N. (2001). Act you age! A cultural construction of adolescence. London: Routledge Falmer.

Llewellyn, A. (2012). Unpacking understanding: The (re)search for the Holy Grail of mathematics education. Educational Studies in Mathematics, 81(3), 385-399.

Ma, L. (1999). Knowing and teaching elementary mathematics. Mahwah: Lawrence Erlbaum.

MacLure, M. (2003). Discourse in educational and social research. Buckingham: Open University Press.

MacLure, M. (2010). The offence of theory. Journal of Education Policy, 25(2), 277-286.

Martin, D. (2010 March). Not-so-strange bedfellows: Racial projects and the mathematics education enterprise. Paper presented at Mathematics Education and Society, Berlin, Germany, 20-25.

Mendick, H. (2005). A beautiful myth? The gendering of being/doing 'good at maths'. Gender and Education, 17(2), 89-105. 
Mendick, H. (2006). Masculinities in mathematics. Maidenhead: Open University Press (McGraw-Hill Education).

Mendick, H. (2008). Subtracting difference: Troubling transitions from GCSE to AS-level mathematics. British Educational Research Journal, 34(6), 711-732.

Mendick, H., \& Francis, B. (2012). Boffin and geek identities: Abject or privileged? Gender and Education, 24(1), 15-24.

Moreau, M. P., Mendick, H., \& Epstein, D. (2010). Constructions of mathematicians in popular culture and learners' narratives: A study or mathematical and non-mathematical subjectivities. Cambridge Journal of Education, 40(1), 25-38.

Nolan, K. (2011). Dispositions in the field: Viewing mathematics teacher education through the lens of Bourdieu's social field theory. Educational Studies in Mathematics, 76(1), 87-100.

Rose, N. (1999). The powers of freedom: Reframing political thought. London: Routledge.

Rowland, T., Turner, F., Thwaites, A., \& Huckstep, P. (2009). Developing primary mathematics teaching: Reflecting on practice with the knowledge quartet. London: Sage.

Said, E. W. (1995). Orientalism: Western conceptions of the Orient. London: Penguin.

Shulman, L. S. (1999). Introduction. In L. Ma (Ed.), Knowing and teaching elementary mathematics. Mahwah: Lawrence Erlbaum.

Skeggs, B. (2004). Class, self, culture. London: Routledge.

Skemp, R. R. (1976). Relational understanding and instrumental understanding. Mathematics Teaching, 77, 20-26.

Smith, A. (2004). Making mathematics count. London: DfES.

Smith, C. (2010). 'Sometimes I think wow I'm doing further mathematics...': Balancing tensions between aspiring and belonging. In B. Atweh, M. Graven, W. Secada, \& P. Valero (Eds.), Mapping equity and quality in mathematics education. Dordrecht: Springer.

Smith, C. (2012). Choosing more mathematics: An exploration of participation and learning in the Further Mathematics Network. Unpublished PhD thesis, London, London Metropolitan University.

Solomon, Y. (2008). Mathematical literacy: Developing identities of inclusion. New York: Routledge.

Walkerdine, V. (1984). Developmental psychology and the child-centred pedagogy: The insertion of Piaget into early education. In J. Henriques, W. Hollway, C. Urwin, C. Venn, \& V. Walkerdine (Eds.), Changing the subject: Psychology, social regulation and subjectivity. London: Methuen.

Walkerdine, V. (1988). The mastery of reason: Cognitive development and the production of rationality. London: Routledge.

Walkerdine, V. (1997). Daddy's girl. Hampshire: Macmillan.

Walkerdine, V. (1998). Counting girls out. London: Falmer.

Walshaw, M. (2001). A Foucauldian gaze on gender research: What do you do when confronted with the tunnel at the end of the light? Journal for Research in Mathematics Education, 32(5), 471-492.

Watson, A. (2008). Developing and deepening mathematical knowledge in teaching: Being and knowing. Paper presented at MKiT 6, University of Loughborough, 18th March. Nuffield Seminar Series.

Zazkis, R., \& Leikin, R. (2010). Advanced mathematical knowledge in teaching practice: Perceptions of secondary mathematics teachers. Mathematical Thinking and Learning, 12(4), 263-281. 